УДК 614.2

DOI: 10.21668/health.risk/2021.3.06

Научная статья

\title{
К АНАЛИЗУ ФАКТОРОВ РИСКА СМЕРТНОСТИ ОТ ЗЛОКАЧЕСТВЕННЫХ НОВООБРАЗОВАНИЙ МУЖСКОГО НАСЕЛЕНИЯ ПРОМЫШЛЕННЫХ МОНОГОРОДОВ
}

\section{Г.И. Тихонова, М.С. Брылёва}

Научно-исследовательский институт медицины труда имени академика Н.Ф. Измерова, Россия, 105275 , г. Москва, Проспект Буденного, 31

\begin{abstract}
Изучена смертность взрослого мужского населения от злокачественных новообразований (3Н) в России и арктических моногородах Мончегорск и Норильск, специилизирующихся на производстве никеля, являющегося каниерогеном.

В связи с небольшой численностью населения городов рассчитаны усредненные за восемь лет (2010-2017 г2.) показатели смертности от ЗН для пятилетних возрастных групп и стандартизованные коэффициенты смертности (СКС) для трудоспособного и посттрудоспособного возраста от класса в целом и отдельных локализаций 3 .

На основе данных об особенностях климата в городах, условиях труда на предприятиях и состоянии окружающей среды, сочиально-экономических характеристиках, включая состояние системы здравоохранения, проведен сравнительный анализ смертности в двух парах мужских популячий: г. Мончегорск и Россия; г. Норильск и г. Мончегорск.

В Мончегорске, уровни сочиально-экономического благосостояния и здравоохранения которого близки к среднероссийским, СКС в трудоспособном возрасте был выше, по сравнению с Россией: от класса 3 в в целом - на 34,7 \%; от форм 3Н, специфичных при воздействии никеля: ЗН губы, рта, глотки - выше в 2,2 раза, ЗН желудка - в 1,5 раза.

В Норильске, при сопоставимых условиях труда и худших характеристиках окружающей среды, по сравнению с Мончегорском, смертность в трудоспособном возрасте была ниже: от класса в иелом - на 15,4\%; от 3Н губы, рта, глотки - на 14,0 \%, от ЗН желудка - на 39,3\%. По сравнению с Россией, смертность от 3 Н также была ниже в трудоспособном возрасте, но выше в посттрудоспособном - на 21,6\%.

Организация современной онкологической помощи в Норильске, включающей высокотехнологичные методы диагностики, лечения и реабилитаиии, а также более высокий уровень жизни населения, способствовали снижению смертности и реализации канцерогенных эффектов в более поздние сроки.

Ключевые слова: смертность, злокачественные новообразования, никель, моногорода, факторы риска, высокотехнологичная медицинская помощь.
\end{abstract}

В России в последние десятилетия злокачественные новообразования (ЗН) занимают второетретье место в структуре причин смерти взрослого мужского населения, уступая первое место болезням системы кровообращения и, в отдельные годы, внешним причинам смерти ${ }^{1}$. При этом наиболее неблагополучная онкологическая ситуация наблюдается в промышленных регионах, где расположены предприятия цветной и черной металлургии, химической промышленности, в которых значительная часть населения подвергается воздействию техногенной нагрузки, в том числе канцерогенными веществами [1-5].

В руководящих указаниях по стратегиям и управлению ВО3 «Национальные программы борьбы против рака» указано, что в одной трети случаев заболевания раком предотвратимы, в одной трети - при ранней диагностике излечимы, а паллиативная помощь в оставшейся трети случаев приводит к существенному улучшению качества жизни таких больных [6].

Медно-никелевая промышленность в России включена в перечень канцерогенных производств ${ }^{2}$,

(C) Тихонова Г.И., Брылёва М.С., 2021

Тихонова Галина Ильинична - доктор биологических наук, заведующий лабораторией социально-гигиенических исследований (e-mail: gtikhonova@yandex.ru; тел.: 8 (495) 366-05-66; ORCID: https://orcid.org/0000-0002-1948-4450).

Брылёва Мария Сергеевна - младший научный сотрудник лаборатории социально-гигиенических исследований (e-mail: lms_18@mail.ru; тел.: 8 (495) 366-05-66; ORCID: https://orcid.org/0000-0001-7997-979X).

${ }^{1}$ Демография [Электронный ресурс] // Федеральная служба государственной статистики. - URL: https://www. gks.ru/folder/12781 (дата обращения: 06.09.2019).

${ }^{2}$ ГН 1.1.029-98. Перечень веществ, продуктов, производственных процессов, бытовых и природных факторов, канцерогенных для человека [Электронный ресурс] // Кодекс: электронный фонд правовых и нормативно-технических документов. - URL: https://docs.cntd.ru/document/1200007321 (дата обращения: 06.09.2019). 
а никель и его соединения отнесены по классификации МАИР к I группе опасности, т.е. группе соединений бесспорно канцерогенных для человека [7].

Известно, что на вредных, тяжелых и опасных работах заняты в основном мужчины. В России в 2018 г. доля мужчин, занятых во вредных и опасных условиях труда, составляла от 40 до 60 \% в зависимости от вида экономической деятельности. При этом наиболее высокие показатели отмечаются при добыче полезных ископаемых и в обрабатывающих производствах, а в промышленных регионах эти показатели еще выше и достигают 70-80\%. Подчеркнем, что в России именно для мужского населения характерна сверхсмертность в трудоспособном возрасте [8].

Важнейшим фактором, влияющим на уровни смертности в промышленных моногородах, является санитарно-гигиеническая обстановка, т.е. условия труда, в которых занята значительная часть мужского населения города, и состояние окружающей среды, обусловленное видом деятельности градообразующих предприятий. Вместе с тем уровни смертности населения формируются под влиянием всей совокупности условий жизнедеятельности, включая климатогеографические, социально-экономические и прочие характеристики, которые могут корректировать или, напротив, усугублять последствия производственной деятельности предприятий.

В связи с изложенным целью исследования явилась оценка роли ведущих факторов риска в формировании смертности от ЗН мужского населения промышленных моногородов.

Материалы и методы. Было выбрано два промышленных моногорода Арктической зоны России, в которых расположены предприятия медноникелевой промышленности, - Мончегорск (Мурманская область), находящийся на Кольском полуострове, и Норильск (Красноярский край), расположенный на полуострове Таймыр.

В ходе исследования изучены производственные, экологические, климатогеографические и социально-экономические характеристики городов Мончегорск и Норильск и проведен сравнительный анализ смертности от онкологических заболеваний в этих городах, а также в России в целом.

Анализ состояния производственной среды на предприятиях изучаемых городов проводился по данным государственных докладов о санитарноэпидемиологическом благополучии населения Мурманской области и Красноярского края, отчетам об устойчивом развитии Группы компаний «Норильский никель» за 2010-2017 гг., материалам исследований, выполненных в ФГУН «Северо-Западный научный центр гигиены и общественного здоровья» и др. [9-13].

Экологическая ситуация в городах изучалась по материалам Мурманского управления по гидрометеорологии и мониторингу загрязнения окружающей среды, Комитета природопользования и экологии Мурманской области, данным Таймырского центра по гидрометеорологии и мониторингу окружающей среды и официальных ежегодников Росгидромет за 2010-2017 гг.

Социально-экономические характеристики городов Мончегорск и Норильск за 2010-2018 гг. изучались на основе официальных статистических ежегодников и баз данных Росстата, а также по данным отчетов, представленных на официальных сайтах городов Мончегорск (monchegorsk.gov-murman.ru) и Норильск (norilsk-city.ru). Дополнительная информация о состоянии системы здравоохранения получена на сайтах учреждений здравоохранения изучаемых городов.

Смертность мужского населения исследуемых городов изучалась на основе статистических данных:

- о половозрастном составе населения за 2010-2017 гг.;

- о числе умерших (ф. С-51 - «Распределение умерших по полу, возрасту и причинам смерти») за 2010-2017 гг.

Данные Мурманскстата о смертности мужчин в посттрудоспособном возрасте были ограничены возрастной группой 70 лет и старше, что было учтено при статистической обработке.

В связи с относительно небольшой численностью городов и возможными сильными колебаниями уровня смертности в отдельные годы были рассчитаны усредненные за восемь лет (2010-2017 гг.) показатели смертности от класса ЗН взрослого мужского населения:

- для пятилетних возрастных групп (15-19, $20-24, \ldots, 85+)$ от класса ЗН в целом;

- стандартизованные по возрасту показатели смертности;

- для трудоспособного возраста (15-59);

- для посттрудоспособного вораста (Мончегорск и Россия (60-70+), Норильск и Россия (60-85+)).

Стандартизованные показатели были рассчитаны для класса ЗН в целом, подклассов ЗН органов дыхания и ЗН органов пищеварения, а также от ведущих локализаций $3 \mathrm{H}$, которые по литературным данным являются специфичными при воздействии никеля: ЗН губы, рта, глотки, ЗН трахеи, бронхов, легких, ЗН желудка [7, 10, 12-18].

Стандартизация проводилась прямым методом. За стандарт принята возрастная структура мужского населения России по переписи 2010 г.

Результаты и их обсуждение. Мончегорск и Норильск расположены в районах Крайнего Севера и находятся практически на одной широте (67 с.ш. Мончегорск и $69^{\circ}$ с.ш. Норильск), однако климатические условия в них резко различаются. В Мончегорске климат более мягкий из-за близости теплого течения Гольфстрим (средние зимние температуры воздуха не опускаются ниже $-18^{\circ} \mathrm{C}$ ). Для Норильска характерны более суровые субарктические климатические условия с температурным режимом до $-53^{\circ} \mathrm{C}$, более высокой скоростью 
ветра, и более продолжительными периодами полярного дня и ночи.

Градообразующими в обоих городах являются предприятия компании ОАО ГМК «Норильский никель». В Мончегорске находится металлургический завод, выпускающий готовую продукцию. В Норильске осуществляется полный цикл производства - предприятия по добыче и обогащению руды и несколько металлургических комбинатов большей мощности.

Главным источником канцерогенной опасности на металлургических заводах являются водорастворимые соединения никеля в воздухе рабочей зоны. В Мончегорске превышение среднесменных допустимых значений по никелю составило 6-37 ПДК [9-11].

Работники металлургических предприятий Норильска подвержены воздействию соединений никеля - среднесменные концентрации от 2,1 до 34 ПДК, а также оксида мышьяка - до 2,3 ПДК [12-13].

Кроме того, в Норильске на предприятиях по добыче и обогащению медно-никелевой руды работники также подвержены влиянию канцерогенных факторов, среди которых пыль никеля, превышение среднесменных допустимых концентраций составляло от 3 до 8 раз в зависимости от профессии, и бенз(а)пирен -1,3 ПДК (машинисты ПДМ) [12].

Наиболее неблагоприятные условия труда складываются на металлургических предприятиях. Основное гигиеническое значение с позиции риска развития ЗН на предприятиях обоих городов имеет никель и его соединения. В организм никель поступает преимущественно через дыхательные пути, желудочно-кишечный тракт и кожу ${ }^{3}$ [17].

Уровни воздействия по никелю между металлургическими предприятиями существенно не различались, что позволяет принять допущение о равнозначной степени канцерогенной опасности, обусловленной условиями труда на предприятиях.

Анализ экологической ситуации показал, что в Мончегорске в числе выбросов, отходящих от стационарных источников, были зафиксированы пыль, диоксид серы, оксид углерода, диоксид азота, а также бенз(а)пирен и формальдегид, являющиеся канцерогенами. При этом превышение среднегодовых концентраций было зафиксировано только для формальдегида (до 2,5 ПДК) ${ }^{4}$. По данным 2018 г. суммарная доля выбросов в атмосферу в Мончегорске составляла 45,7 тысячи тонн. Вместе с тем циклоническая деятельность, характерная для Кольского полуострова, способствует рассеиванию загрязняющих веществ. Комплексный показатель загрязнения атмосферы (ИЗА 5) с учетом основных загрязняющих компонентов за период 2010-2017 гг. не превышал 5,25 , что оценивается как «повышенный» уровень ${ }^{6}$.

В Норильске фиксируется повышенный уровень загрязнения атмосферы вредными веществами 1-го и 2-го классов опасности около 350 дней в году, из них около $80 \%$ с уровнем до 5 ПДК 7 . Превышение отмечается по содержанию диоксида серы, фенола, диоксида и оксида азота, меди, кобальта, содержание которых превышает допустимое значение от 1,3 до 4,2 ПДК. Среднегодовые показатели загрязнения атмосферного воздуха селитебной зоны города канцерогенными веществами превышали установленные показатели по формальдегиду в 9,5 раза, по никелю - в 7,5 раза ${ }^{8}$. Суммарная доля выбросов в атмосферу в Норильске в 2018 г. составила 1798,5 тысячи тонн. Накоплению вредных веществ в атмосфере города способствуют особенности рельефа: город расположен в котловине, закрытой с югозапада и северо-востока хребтами, достигающими 500-900 м. Показатель ИЗА 5 колебался в пределах от 4,19 до 31,4, что позволяет оценить уровень загрязнения как «высокий» и «очень высокий».

Таким образом, загрязнение окружающей среды в изучаемых городах следует оценить как фактор риска развития ЗН. При этом в силу особенностей рельефа местности, а также больших масштабов производства, уровень загрязнения окружающей среды многократно выше в Норильске, входящем в тройку самых грязных городов России'.

${ }^{3}$ Вредные вещества в промышленности. Т. 3: Неорганические и элементорганические соединения: справочник / под ред. Н.В. Лазарева, Э.Н. Левиной. - Л.: Химия, 1977. -608 с.

${ }^{4} \mathrm{O}$ состоянии санитарно-эпидемиологического благополучия населения в Мурманской области: Государственный доклад. - Мурманск: Федеральная служба по надзору в сфере защиты прав потребителей и благополучия человека по Мурманской области, 2010-2018.

Мурманское управление по гидрометеорологии и мониторингу окружающей среды [Электронный ресурс]. URL: http://kolgimet.ru/ (дата обращения: 13.06.2019).

${ }^{6}$ РД 52.04.186-89. Руководство по контролю загрязнения атмосферы / утв. Госкомгидрометом СССР 01.06.1989, Главным государственным санитарным врачом СССР 16.05.1989 [Электронный ресурс] // Кодекс: электронный фонд правовой и нормативно-технической документации. - URL: http:/docs.cntd.ru/document/1200036406 (дата обращения: 24.02.2021).

${ }^{7} \mathrm{O}$ состоянии санитарно-эпидемиологического благополучия населения в Красноярском крае: Государственный доклад. - Красноярск: Федеральная служба по надзору в сфере защиты прав потребителей и благополучия человека по Красноярскому краю, 2010-2018.

${ }^{8}$ Таймырский центр по гидрометеорологии и мониторингу окружающей среды [Электронный ресурс]. - URL: http://www.meteorf.ru/about/structure/cgms/3154/ (дата обращения: 30.06.2019).

${ }^{9}$ РД 52.04.186-89. Руководство по контролю загрязнения атмосферы / утв. Госкомгидрометом СССР 01.06.1989, Главным государственным санитарным врачом СССР 16.05.1989 [Электронный ресурс] // Кодекс: электронный фонд правовой и нормативно-технической документации. - URL: http://docs.cntd.ru/document/1200036406 (дата обращения: 24.02.2021). 
Изучение социально-экономических характеристик показало, что по данным 2018 г. средняя заработная плата в России составила 43724 руб., в Мончегорске уровень заработной платы был выше примерно на треть - 59734 руб., а в Норильске более чем в два раза - 93129 руб. ${ }^{10}$. Изучение других социально-экономических характеристик свидетельствовало, что уровень жизни в Мончегорске по большинству показателей незначительно превышает среднероссийский, в то время как в Норильске был намного выше. Например, доля лиц с доходами ниже прожиточного минимума в России составляла $12,9 \%$, в Мончегорске - 10,8 \%, в Норильске почти вдвое ниже общероссийского - 6,6 \%; уровень безработицы в России составлял 4,8\%, в Мончегорске$2,2 \%$, в Норильске - 0,8 \%; объем инвестиций на душу населения составлял 119,8 тысячи руб., 171,2 тысячи руб. и 524,9 тысячи руб. соответственно ${ }^{11}$.

Ocобое внимание при анализе социальноэкономических условий в городах уделялось качеству медицинской помощи и организации системы здравоохранения. По официальным показателям состояния системы здравоохранения различия между городами Мончегорск, Норильск, а также Россией были несущественными: показатель обеспеченности населения врачами на 10 тысяч населения составил 54,9, 50,9, 47,5 соответственно, средним медицинским персоналом - 146,6, 189,5, 103,8, больничными койками - 84,2, 70,1, 80,5 на 10 тысяч населения соответственно. Однако, с позиции зрения сохранения здоровья населения и снижения смертности, в настоящее время все большее значение приобретают высокотехнологичные методы диагностики и лечения, уровень квалификации кадров и укомплектованность штатов. Это необходимо для эффективного использования сложного уникального оборудования, особенно применительно к двум ведущим классам болезней, являющихся основными причинами смерти: болезням системы кровообращения и ЗН. В связи с этим был проведен углубленный анализ системы онкологической помощи населению в изучаемых моногородах.

В Мончегорске на базе центральной городской больницы осуществляет работу только первичный онкологический кабинет, а верификация диагноза и последующее лечение возможно только на базе Мурманского областного онкологического диспансера, который тоже недостаточно оснащен рентгенологическим и эндоскопическим оборудованием. В предписаниях Роспотребнадзора, Госпожнадзора, Росздравнадзора отмечены также недоукомплектованность штата врачами-онкологами и неудовлетворительное состояние здания учреждения. Такое по- ложение значительно затрудняет выявление ЗН на ранних стадиях и может служить причиной запущенности онкологических заболеваний и, соответственно, высоких уровней летальности [19].

Качество медицинской помощи в Норильске иное. Норильская больница является единственной многоэтажной 1000-коечной больницей во всем мировом Заполярье. Онкологическое отделение оснащено самым современным высокотехнологичным оборудованием, укомплектовано специалистами высокой квалификации, что позволяет осуществлять комплексную и быструю диагностику злокачественных новообразований, широко использовать щадящие способы лечения, в том числе методы малоинвазивной хирургии и др. В городе осуществляются медико-профилактические программы, в том числе программы онкоскрининга с особым вниманием к заболеваниям, специфичным при воздействии никеля: хронические и предраковые состояния органов пищеварения, новообразования губы, рта, глотки. В рамках регионального проекта «Борьба с онкологическими заболеваниями» на базе Норильской поликлиники действует центр амбулаторной онкологической помощи, где проводится ежегодная диспансеризация населения в возрасте старше 40 лет [20].

Таким образом, большинство показателей, отражающих уровень социально-экономического благополучия населения, а также характеристики системы здравоохранения в Мончегорске были близки к средним по России, в то время как в Норильске по указанным параметрам уровень значительно более высокий.

Известно, что демографические проблемы тесно связаны с экономическим и социальным развитием. Демографическая ситуация в Мончегорске характеризуется теми же проблемами, что существуют и в стране в целом: снижение численности населения, отток молодежи в крупные центры, вследствие чего происходит интенсивное «старение» населения, которое усугубляется низкой рождаемостью и высокими уровнями смертности, особенно у мужчин трудоспособного возраста. В России, по данным 2018 г., общий коэффициент смертности составил 12,0%о и был выше коэффициента рождаемости - 11,0 \%. В Мончегорске смертность еще более превышала рождаемость, общие коэффициенты смертности и рождаемости составили соответственно 12,6 и 9,0 \%о ${ }^{12}$.

В Норильске демографическая ситуация принципиально отличается от характерной для зоны Арктики и России в целом. В городе отмечается «молодая» возрастная структура населения с более высокой долей лиц трудоспособного возраста $68,7 \%$, что выше по сравнению с Мончегорском и Россией на 10,6 и 12,7\% соответственно по дан-

${ }^{10}$ Демография [Электронный ресурс] // Федеральная служба государственной статистики. - URL: https://www. gks.ru/folder/12781 (дата обращения: 06.09.2019)

${ }^{11}$ Там же.

${ }^{12}$ Там ж. 
ным за 2018 г. ${ }^{13}$ Экономическая привлекательность города обусловливает стабильный миграционный приток населения, преимущественно молодого возраста. Вместе с тем рост численности населения происходит преимущественно за счет естественного прироста, общий коэффициент рождаемости в Норильске в 2018 г. составил 13,1\% ${ }^{14}$

Рассмотренные факторы производственной и непроизводственной природы могут оказывать влияние не только на общие демографические показатели, но и на уровни смертности от онкологических заболеваний.

С учетом различий в возрастной структуре, связанных как с естественным, так и с механическим движением населения, для сравнительного анализа были использованы повозрастные показатели смертности в пятилетних возрастных группах, а также стандартизованные по возрасту показатели смертности отдельно для трудоспособного (15-59 лет) и посттрудоспособного возраста (60 лет и старше). Это позволило устранить влияние различий в возрастном составе мужского населения сравниваемых территорий при оценке уровня смертности.
Для оценки влияния производственной деятельности предприятия на показатели здоровья был проведен сравнительный анализ смертности в мужских популяциях г. Мончегорска и России, поскольку уровень социально-экономического развития и системы здравоохранения в моногороде был весьма близок к среднему по России, а основное отличие заключалось в расположении на его территории канцерогенного медно-никелевого производства.

Для оценки влияния социально-экономических и иных факторов, не связанных с производством, проводилось сравнение показателей смертности в Норильске и Мончегорске, в которых расположены предприятия медно-никелевой промышленности, характеризующиеся сопоставимыми условиями труда, но различающиеся по уровню жизни и состоянию системы здравоохранения, принимая во внимание худшие климатические и экологические условия в Норильске.

На рисунке, $a$, представлены коэффициенты смертности от ЗН, усредненные за 2010-2017 гг., для отдельных возрастных групп мужского населения трудоспособного возраста (15-59 лет) Мончегорска, России и Норильска.
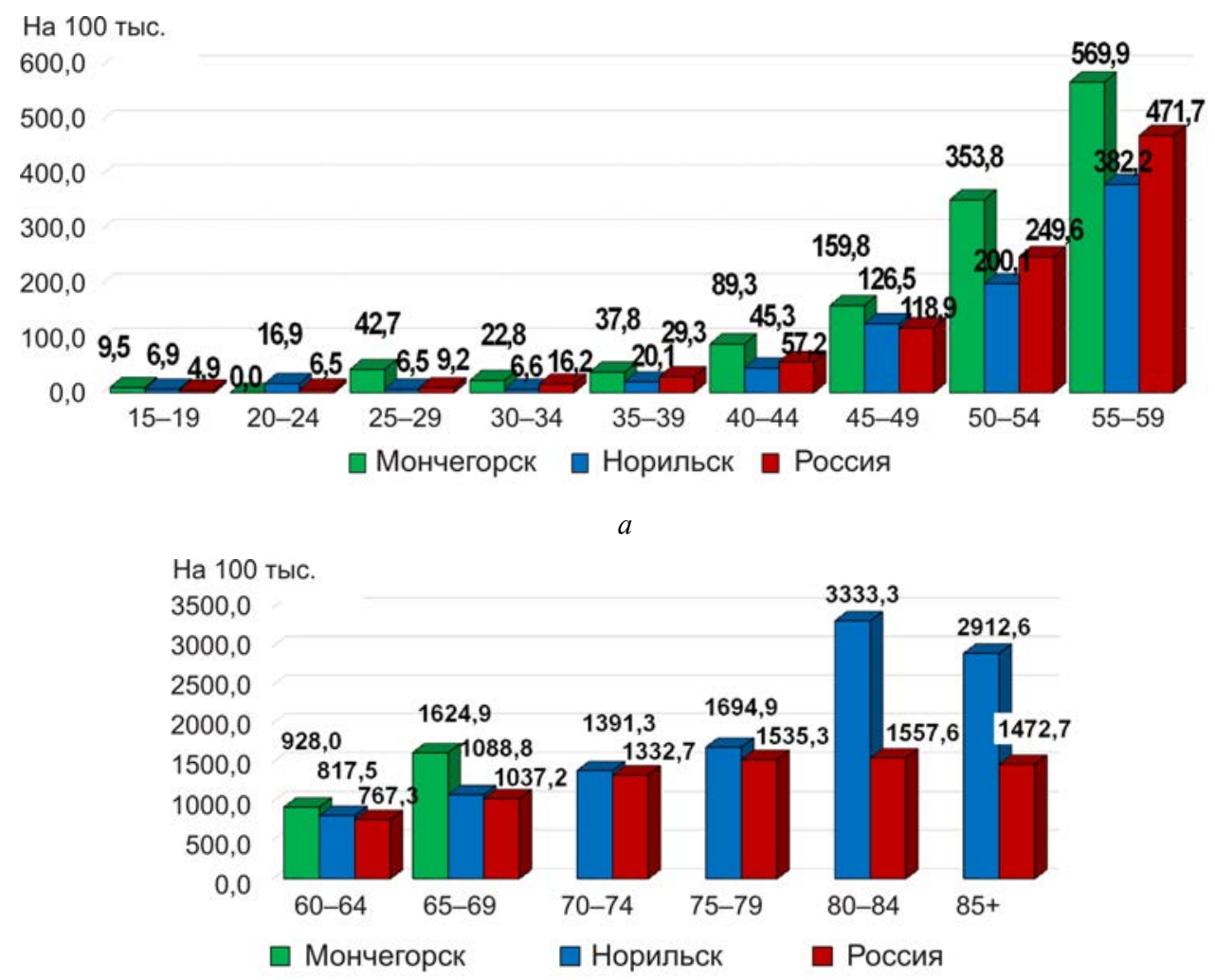

$\sigma$

Рис. Показатели смертности от злокачественных новообразований мужского населения г. Мончегорска, Норильска и России по 5-летним возрастным группам в среднем за 2010-2017 гг. (на 100 тысяч соответствующего возраста): $a$ - в интервале трудоспособного возраста; $\sigma$ - в посттрудоспособном возрасте

${ }^{13}$ Демография [Электронный ресурс] // Федеральная служба государственной статистики. - URL: https://www. gks.ru/folder/12781 (дата обращения: 06.09.2019).

${ }^{14}$ Там же. 
Стандартизованные коэффициенты смертности от злокачественных новообразований мужского населения г. Мончегорска, г. Норильска и России в трудоспособном и посттрудоспособном возрасте на 100 тысяч населения соответствующего возраста

\begin{tabular}{|c|c|c|c|c|c|c|}
\hline Территория & Bce $3 \mathrm{H}$ & $\begin{array}{c}\text { 3Н органов } \\
\text { дыхания }\end{array}$ & $\begin{array}{c}\text { 3Н трахеи, брон- } \\
\text { хов, легких }\end{array}$ & $\begin{array}{c}\text { 3Н органов } \\
\text { пищеварения }\end{array}$ & ЗН желудка & $\begin{array}{c}\text { ЗН губы, полости } \\
\text { рта и глотки }\end{array}$ \\
\hline & \multicolumn{6}{|c|}{ Трудоспособный возраст (15-59) } \\
\hline Мончегорск & 133,8 & 37,0 & 32,5 & 42,2 & 15,9 & 16,4 \\
\hline Норильск & 84,0 & 25,7 & 22,3 & 31,1 & 6,6 & 6,5 \\
\hline \multirow[t]{2}{*}{ Россия } & 99,4 & 30,9 & 26,8 & 33,4 & 10,8 & 7,5 \\
\hline & \multicolumn{6}{|c|}{ Посттрудоспособный возраст (по усеченным данным 60-70+) } \\
\hline Мончегорск & 1204,6 & 317,3 & 298,9 & 441,3 & 156,3 & 73,6 \\
\hline \multirow[t]{2}{*}{ Россия } & 1134,1 & 329,1 & 297,0 & 427,5 & 135,4 & 41,9 \\
\hline & \multicolumn{6}{|c|}{ Посттрудоспособный возраст (60-85+) } \\
\hline Норильск & 1367,9 & 414,2 & 387,3 & 476,9 & 138,9 & 43,9 \\
\hline Россия & 1124,7 & 331,6 & 299,1 & 422,5 & 134,2 & 42,4 \\
\hline
\end{tabular}

Анализ свидетельствует, что уровни смертности в Мончегорске по сравнению с Россией и Норильском практически во всех возрастных группах были выше. В Норильске, напротив, большинство повозрастных показателей смертности от ЗН у мужчин были ниже, не только по сравнению с Мончегорском, но и с Россией.

В двух возрастных группах старше 60 лет также наиболее высокие уровни смертности наблюдались в Мончегорске (рисунок, б).

В посттрудоспособном возрасте соотношение показателей между Россией и Норильском изменилось. Уровень смертности в Норильске превышал средние показатели по России во всех старших возрастных группах, достигая максимальных различий в возрасте старше 80 лет.

Стандартизованные по возрасту показатели смертности мужского населения отдельно для трудоспособного и для посттрудоспособного возраста представлены в таблице.

Стандартизованный показатель смертности мужского населения трудоспособного возраста от $3 \mathrm{H}$ в Мончегорске был выше по сравнению с Россией на 34,7 \% (133,8 и 99,4 на 100 тысяч мужчин трудоспособного возраста соответственно). Превышение наблюдалось также для подкласса ЗН органов дыхания - на 19,7 \%, в том числе от ЗН трахеи, легких, бронхов на 21,5 \%. Максимальные различия наблюдались для форм новообразований, специфичных при воздействии никеля: 3 Н желудка в 1,5 раза выше по сравнению с Россией, ЗН губы, рта, глотки в 2,2 раза выше (см. таблицу).

Проведенный анализ смертности по усеченным данным для посттрудоспособного возраста также свидетельствовал о повышенных уровнях смертности мужского населения Мончегорска по сравнению с Россией от класса 3 Н в целом на $6,2 \%$. Причем наибольшее превышение наблюдалось от тех нозологических форм, которые являются органамимишенями при воздействии никеля: от $3 \mathrm{H}$ желудка на $15,4 \%$ и от ЗН губы, рта, глотки - в 1,7 раза.

В Норильске повозрастные показатели смертности и стандартизованные коэффициенты смертности мужчин трудоспособного возраста за восьмилетний период наблюдения были ниже как по сравнению с Мончегорском, так и по сравнению с Россией.

Более низкие показатели смертности наблюдались и от анализируемых подклассов и нозологических форм новообразований. Показатель смертности от ЗН органов дыхания, в том числе от ЗН трахеи, бронхов, легких, стандартизованный коэффициент смертности мужчин трудоспособного возраста в Норильске был на треть ниже, чем в Мончегорске, и почти на 17 \% ниже, чем в России. Показатель смертности от ЗН органов пищеварения в Норильске в трудоспособном возрасте была ниже на 26,2 и 6,9\% по сравнению с Мончегорском и Россией соответственно, в том числе от 3 ж желудка в 2,4 и 1,6 раза соответственно. Смертность от ЗН губы, рта, глотки в 2,5 раза ниже, чем в Мончегорске, и на 14,0\% ниже, чем в России.

Многолетнее исследование смертности от ЗН в г. Мончегорске, социально-экономическое развитие которого, а также демографические характеристики и проблемы системы здравоохранения соответствовали ситуации, наблюдающейся в среднем по стране, выявило более высокие уровни смертности от данного класса причин по сравнению с Россией.

Подобные результаты были получены в работах других отечественных и зарубежных исследователей, свидетельствующих о высоком риске развития ЗН как среди работников медно-никелевого производства, так и среди населения городов, в которых оно расположено [15, 16, 21-23].

O повышенных показателях онкологической заболеваемости работников никелевой промышленности свидетельствуют работы В.П. Артюниной, Г.П. Чащина и др. [21]. По данным авторов, при многократном превышении ПДК никеля показатели онкологической заболеваемости среди работающих на этих предприятиях более чем в три раза выше аналогичных данных для населения. При этом наибольшие различия получены для рака легких [21].

В статье Г.И. Тихоновой, Т.Ю. Горчаковой, А.Н. Чурановой [23] были проанализированы уровни смертности мужского населения трудоспособно- 
го возраста в городах Мурманской области в зависимости от специфики градообразующих предприятий. Установлено, что у мужского населения трудоспособного возраста в г. Мончегорске по сравнению с г. Мурманском, в котором отсутствовали крупные промышленные предприятия, были повышены показатели смертности от 3 Н на $17,1 \%$, в том числе от ЗН органов дыхания - на 8,5 \%, ЗН органов пищеварения - на 26,7 \%, от ЗН губы, рта и глотки на $80,2 \%$ [23].

В исследовании заболеваемости злокачественными новообразованиями среди работников электролизного производства никелевого завода ПортКолборн (Онтарио, Канада) за период с 1930 по 1992 г. был показан повышенный риск развития 3Н полости носа и носоглотки независимо от уровней воздействия соединений никеля [15].

В работе M. Pavela, J. Uitti, E. Pukkala [16] представлены данные исследования онкологической заболеваемости среди рабочих, занятых на никелевом и нефтеперерабатывающем заводах в Харьявалте, Финляндия. Была изучена заболеваемость ЗН среди 1115 человек, подвергшихся воздействию никеля. Группу сравнения составили 194 человека, не подвергшихся воздействию никеля на рабочих местах. Период исследования составил 45 лет - с 1967 по 2011 г. В работе показано, что воздействие соединений никеля является основной причиной повышенного риска развития рака полости носа и рака легких у работников никелевого завода. Общее число случаев рака у мужчин составило 251 (стандартизованный коэффициент заболеваемости $(S I R)-1,05$, $95 \%)$, а у женщин - 12 (SIR - 1,22, 95 \%). При этом на рабочих местах, где уровни воздействия никеля были наибольшими, было зарегистрировано 14 случаев рака легких $(S I R-2,01,95 \%)$ и три случая рака полости носа (SIR - 26,7, 95 \%) [16].

B работе V. Ciannameo et. al [22] изучена связь воздействия никеля со смертностью в когорте из 2991 итальянского работника гальванического производства. Результаты исследования показали, что воздействие соединений никеля может увеличить риск развития рака легких, даже при уровнях профессионального воздействия ниже предельно допустимой концентрации. Также в исследовании выявлена связь воздействия никеля с развитием ЗН органов пищеварения и ЗН почек [22].

Таким образом, выявленное в представленном исследовании превышение смертности от ЗН мужского населения г. Мончегорска, преимущественно занятого на градообразующем предприятии, согласуется с результатами исследований других отечественных и зарубежных авторов. Это позволяет оценивать повышенные уровни смертности от рака взрослого мужского населения как негативное последствие для здоровья, профессиональных и экологических рисков, связанных с производственной деятельностью градообразующего предприятия.
В Норильске можно было бы ожидать еще более высоких показателей смертности от $3 \mathrm{H}$, поскольку условия труда на предприятиях также сопряжены с риском развития $3 \mathrm{H}$, а загрязнение окружающей среды, по сравнению с Мончегорском, значительно выше, в том числе канцерогенными веществами, и может усугубляться более суровыми климатическими условиями. Это предположение подтверждали имеющиеся в литературе данные о высоких уровнях онкологической заболеваемости в Норильске, показанные в работах О.А. Ананиной с соавт. [24], Д.В. Горяева, И.В. Тихоновой [25], В.В. Карасева с соавт. [26], Б.А. Ревича [4].

Представленный выше анализ уровня социально-экономического развития и состояния медикопрофилактической помощи населению позволяет утверждать, что низкая смертность мужского населения трудоспособного возраста от ЗН в Норильске по сравнению с Мончегорском в значительной степени обеспечена высокой эффективностью работы учреждений здравоохранения. Большую роль в снижении смертности от новообразований играет выявление болезни на ранней стадии, чему способствуют внедренные в г.Норильске программы онкоскрининга, рассчитанные на привлечение дополнительных групп населения к участию в медицинских осмотрах, и особое внимание специалистов к тем локализациям 3Н, которые специфичны для никеля. На это указывают крайне низкие уровни смертности от ЗН желудка и ЗН губы, рта, глотки в трудоспособном возрасте и (практически не превышающие российские показатели) в посттрудоспособном (от ЗН желудка в Норильске выше на 3,5 \%, от ЗН губы, рта, глотки - на 3,6\%). Это важно отметить, поскольку в посттрудоспособном возрасте смертность от класса ЗН в целом в Норильске была выше по сравнению с Россией на 21,6 \%.

Значимость совершенствования системы онкологической помощи в улучшении показателей качества и продолжительности жизни больных со злокачественными новообразованиями также подтверждена в работах ряда отечественных и зарубежных авторов [27-29].

Анализ всего комплекса полученных результатов свидетельствует, что в Норильске, как и в Мончегорске, существует высокий, а вероятно, исходя из гигиенических характеристик, и более высокий, риск развития 3Н, но смертность от данного класса причин смещена в сторону старших возрастных периодов. Выявленную закономерность можно оценивать как отсроченную реализацию онкологического риска, обусловленного техногенными факторами, но скорректированного влиянием более совершенной организации системы здравоохранения, в том числе более эффективной онкологической помощи, а также более высоким уровнем жизни населения.

Итак, исследование смертности от онкологических заболеваний в г. Норильске показало, что в условиях промышленного моногорода с канцерогенным 
производством медицинская составляющая, то есть раннее выявление, своевременное и эффективное лечение и последующая реабилитация, оказывают решающее влияние на уровень смертности от $3 \mathrm{H}$, особенно в трудоспособном возрасте.

Таким образом, производственная деятельность градообразующего предприятия может оказывать негативное влияние на состояние здоровья работников и жителей города, но это же предприятие является основным источником социального и экономического благополучия населения, обеспечивая жизнедеятельность моногорода [23]. Причем на тех территориях, где бизнес проводит социально ответственную политику, профессиональные и экологические риски могут быть значительно снижены. Указанное может служить основой для формирования социально-демографической и корпоративной политики, направленной на сохранение здоровья и снижение смертности работников и населения в промышленных моногородах.

\section{Выводы:}

1. Проведенное социально-гигиеническое исследование смертности мужского взрослого населения в двух промышленных моногородах и России позволило дать дифференцированную оценку последствий воздействия факторов, связанных с производственной деятельностью медно-никелевых предприятий, в процессе сравнительного анализа смертности в г. Мончегорске и России и непроизводственных факторов при сопоставлении смертности в городах Норильске и Мончегорске.

2. В г. Мончегорске, по сравнению с Россией, при близких социально-экономических характери- стиках и состоянии системы здравоохранения были выявлены более высокие уровни смертности мужского населения от класса ЗН в целом и его отдельных локализаций, специфичных при воздействии никеля, что позволяет связать выявленные различия с воздействием вредных производственных факторов и загрязненной окружающей среды.

3. Установлено, что при сопоставимых параметрах производственных факторов на предприятиях моногородов в г. Норильске, с худшими характеристиками состояния окружающей среды и климата, повозрастные показатели смертности мужского населения во всех пятилетних группах были ниже, по сравнению с Мончегорском, что обусловлено более высоким качеством жизни, в том числе широкой доступностью медико-профилактической помощи, включая высокотехнологичные методы диагностики, лечения и реабилитации больных с новообразованиями.

4. В г. Норильске, по сравнению с Россией, на фоне более низких стандартизованных показателей смертности мужчин в возрасте до 60 лет в посттрудоспособном возрасте регистрировались более высокие уровни смертности, то есть онкологический риск сохранялся, хотя реализовывался в более поздние сроки, что указывает на приоритетность мер гигиенического характера, направленных на улучшение условий труда и экологической ситуации.

Финансирование. Исследование не имело финансовой поддержки.

Конфликт интересов. Авторы заявляют об отсутствии конфликта интересов.

\section{Список литературы}

1. Анализ канцерогенного риска при воздействии факторов окружающей среды на здоровье населения крупного промышленного города и заболеваемость злокачественными новообразованиями / В.М. Боев, Л.В. Зеленина, Д.А. Кряжев, Л.М. Тулина, А.А. Неплохов // Здоровье населения и среда обитания. - 2016. - Т. 279, № 6. - С. 4-7.

2. Шуц Д., Олссон Э. На пути к ликвидации профессионального рака в Российской Федерации: исследования, направленные на профилактику онкологических заболеваний (Часть 1) // Медицина труда и промышленная экология. 2019. - № 2. - C. 104-106. DOI: 10.31089/1026-9428-2019-2-104-106.

3. Гигиеническая оценка канцерогенного риска и онкологической заболеваемости населения, проживающего в зоне влияния мест складирования отходов горнорудного комбината / И.В. Май, С.В. Клейн, С.А. Вековшинина, С.С. Ханхареев, Е.В. Мадеева, М.А. Землянова, О.В. Долгих // Здоровье населения и среда обитания. - 2018. - № 5. - С. $40-47$.

4. Ревич Б.А. Риски здоровью населения в «горячих точках» от химического загрязнения Арктического макрорегиона // Проблемы прогнозирования. - 2020. - № 2. - С. 148-157.

5. Ambient Air Pollution and Cancer Mortality in the Cancer Prevention Study II / M.C. Turner, D. Krewski, W.R. Diver, C.A. Pope 3rd, R.T. Burnett, M. Jerrett, J.D. Marshall, S.M. Gapstur // Environ Health Perspect. - 2017. - Vol. 125, № 8. P. 087013: DOI: 10.1289/EHP1249

6. National cancer control programs: policies and managerial guidelines. - 2nd ed. // World Health Organization. - 2002. URL: https://apps.who.int/iris/handle/10665/42494 (дата обращения: 06.09.2019)

7. Chromium, Nickel and Welding // IARC Monographs on the Evaluation of Carcinogenic Risks to Humans, vol. 49. IARC Lyon, France, 1990. - 677 p.

8. Условия труда как фактор риска повышения смертности в трудоспособном возрасте / И.В. Бухтияров, Н.Ф. Измеров, Г.И. Тихонова, А.Н. Чуранова, Т.Ю. Горчакова, М.С. Брылева, А.А. Крутко // Медицина труда и промышленная экология. - 2017. - № 8. - С. 43-49.

9. Никанов А.Н., Чащин В.П. Гигиеническая оценка экспозиции и определение ее величины при производстве никеля, меди и кобальта на горнометаллургическом комплексе Кольского Заполярья // Экология человека. - 2008. № 10. - C. 9-14.

10. Рочева И.И., Лештаева Н.Р. Условия труда и состояние здоровья работниц на предприятиях никелевого производства Кольского заполярья // Экология человека. - 2008. - № 10. - С. 47-49. 
11. Сюрин С.А., Горбанев С.А. Влияние условий и продолжительности труда на здоровье горняков северных рудников // Медицина труда и промышленная экология. - 2018. - № 5. - C. 44-49. DOI: 10.31089/1026-9428-2018-5-44-49

12. Серебряков П.В. Роль никельсодержащих аэрозолей в формировании злокачественных новообразований желудочно-кишечного тракта // Российский журнал гастроэнтерологии, гепатологии, колопроктологии. - 2007. - Т. 17, № 3. - С. 78-84.

13. Серебряков П.В., Федина И.Н., Рушкевич О.П. Особенности формирования злокачественных новообразований органов дыхания у работников предприятий по добыче и переработке медно-никелевых руд // Медицина труда и промышленная экология. - 2018. - № 9. - C. 9-15. DOI: https://doi.org/10.31089/1026-9428-2018-9-9-15

14. Nickel in the Human Environment // IARC Scientific Publications, No. 53. - IARC Lyon, France 1984. - 236 p.

15. Grimsrud T.K., Andersen A. Unrecognized risks of nickel-related respiratory cancer among Canadian electrolysis workers // Scand. J. Work Environ. Health. - 2012. - Vol. 38, № 6. - P. 503-515. DOI: 10.5271/sjweh.3274

16. Pavela M., Uitti J., Pukkala E. Cancer incidence among copper smelting and nickel refining workers in Finland // Am. J. Ind. Med. - 2017. - Vol. 60, № 1. - P. 87-95. DOI: 10.1002/ajim.22662

17. Профессиональные злокачественные новообразования легких и других локализаций и потенциально опасные производственные канцерогены / С.А. Бабанов, Д.С. Будаш, А.Г. Байкова, Н.С. Рыжова // Consilium Medicum. - 2017. № 11. - С. 39-46. DOI: 10.26442/2075-1753_19.11.39-46

18. Результаты оценки канцерогенной опасности с поэтапной реализацией комплекса санитарно-гигиенических и медико-профилактических мероприятий / В.Б. Гурвич, С.В. Кузьмин, Г.Я. Липатов, В.И. Адриановский, Н.В. Зебзеева, О.Ю. Береснева, Т.В. Бушуева, В.О. Рузаков // Вестник Уральской медицинской академической науки. - 2015. - № 2. C. 43-46.

19. Состояние онкологической помощи на территории Мурманской области [Электронный ресурс] // Российская ассоциация паллиативной медицины. - 2019. - URL: https:/palliamed.ru〉files/download/file1231.html (дата обращения: 06.09.2019).

20. Маршрутизацию онкопациентов и работу центров онкологической помощи (ЦАОП) обсудили медики Красноярского края [Электронный ресурс] // Министерство здравоохранения Красноярского края. - 2020. - URL: https://kraszdrav.ru/news/8622 (дата обращения: 13.02.2020).

21. Проблемы профессиональной патологии в никель-кобальтовой промышленности / Г.П. Артюнина, В.П. Чащин, С.А. Игнатькова, 3.Н. Остапяк, А.Н. Никанов, Л.В. Талыкова [и др.] // Гигиена и санитария. - 1998. - № 1. - С. 9-13.

22. Cancer mortality and exposure to nickel and chromium compounds in a cohort of Italian electroplaters / V. Ciannameo, F. Ricceri, S. Soldati, C. Scarnato, A. Gerosa, G. Giacomozzi, A. d’Errico // Am. J. Ind. Med. - 2019. - Vol. 62, № 2. P. 99-110. DOI: 10.1002/ajim.22941

23. Тихонова Г.И., Горчакова Т.Ю., Чуранова А.Н. Смертность населения трудоспособного возраста в промышленных городах в зависимости от специфики градообразующих предприятий // Медицина труда и промышленная экология. - 2013. - № 10. - С. 9-15.

24. Заболеваемость злокачественными новообразованиями населения г. Норильска. Формирование групп повышенного риска / О.А. Ананина, Л.Ф. Писарева, И.Н. Одинцова, Е.Л. Христенко, А.Г. Попкова, И.Д. Христенко // Сибирский онкологический журнал. - 2013. - № 4. - С. 58-61.

25. Горяев Д.В., Тихонова И.В. Особенности территориального распределения и динамики показателей неинфекционной заболеваемости населения Красноярского края, ассоциированной с воздействием факторов риска окружающей среды // Анализ риска здоровью. - 2016. - № 4. - С. 54-63. DOI: 10.21668/health.risk/2016.4.07

26. Заболеваемость населения Норильского промышленного района раком легкого / В.В. Карасев, А.Е. Детцель, В.А. Штарик, Ю.А. Дыхно // Вопросы онкологии. - 1992. - Т. 38, № 11. - С. 1340-1344.

27. Состояние онкологической помощи населению Самарской области и направления ее совершенствования / А.Г. Егорова, А.Е. Орлов, М.О. Воздвиженский, С.В. Козлов // Вестник новых медицинских технологий. - 2016. - Т. 23, № 1. - C. 158-164. DOI: $10.12737 / 18502$

28. Annual report to the nation on the status of cancer, 1975-2006, featuring colorectal cancer trends and impact of interventions (risk factors, screening, and treatment) to reduce future rate / B.K. Edwards, E. Ward, B.A. Kohler, C. Eheman, A.G. Zauber, R.N. Anderson, A. Jemal, M.J. Schymura [et al.] // Cancer. - 2010. - Vol. 116, № 3. - P. 544-573. DOI: 10.1002/cncr.24760

29. Loud J.T., Murphy J. Cancer Screening and Early Detection in the 21st Century // Semin. Oncol. Nurs. - 2017. Vol. 33, № 2. - P. 121-128. DOI: 10.1016/j.soncn.2017.02.002

Тихонова Г.И., Брылёва М.С. К оченке факторов риска смертности от злокачественных новообразований мужского населения промышленных моногородов // Анализ риска здоровью. - 2021. - № 3. - C. 67-77. DOI: 10.21668/health.risk/2021.3.06 
UDC 614.2

DOI: $10.21668 /$ health.risk/2021.3.06.eng

Research article

\section{ON ASSESSING RISK FACTORS THAT CAUSE MORTALITY DUE TO MALIGNANT NEOPLASMS AMONG MEN LIVING IN INDUSTRIAL MONOTOWNS}

\section{G.I. Tikhonova, M.S. Bryleva}

Izmerov Research Institute of Occupational Health, 31 Budennogo Ave., Moscow, 105275, Russian Federation

The paper dwells on examining mortality among men due to malignant neoplasms (MNs) in Russia and in Norilsk and Monchegorsk, two monotowns located in the Arctic zone with the only industry there being nickel production. Nickel is a well-known carcinogen.

Given rather small population numbers in these two towns, the authors calculated mortality due to MNs that was averaged over 8 years (2010-2017) for 5-year age groups and standardized mortality ratios (SMR) for employable and postemployable ages as per this nosology in general and specific MNs localizations as well.

Mortality was comparatively analyzed in two male populations in the following pairs: Monchegorsk and Russia, Norilsk and Russia; the analysis was based on data on climatic peculiarities in the towns, working conditions at industrial enterprises, ecological situation, and socioeconomic features including an existing situation in public healthcare.

Socioeconomic welfare and public healthcare quality were close to average Russian ones in Monchegorsk, but SMR for employable population was higher than on average in the country: due to MNs in general, by $34.7 \%$; nickel-specific MNs such as MNs of the lip, mouth, and throat, by 2.2 times; MNs in the stomach, by 1.5 times.

In Norilsk working conditions were similar to those in Monchegorsk but the environmental conditions were worse; still, mortality among employable population was lower: due to MNs in general, by $15.4 \%$; MNs of the lip, mouth, and throat, by $14.0 \%$; due to MNs in the stomach, by $39.3 \%$. In comparison with Russia as a whole, mortality due to MNs was also lower at employable age but higher by $21.6 \%$ at post-employable one.

A decrease in MNs-related mortality and carcinogenic effects becoming apparent at older ages were achieved due to organizing up-to-date oncologic aid in Norilsk including high-tech diagnostic, treatment, and rehabilitation procedures as well as due to higher living standards in the town.

Key words: mortality, malignant neoplasms, nickel, monotowns, risk factors, high-tech medical aid.

\section{References}

1. Boev V.M., Zelenina L.V., Kryazhev D.A., Tulina L.M., Neplokhov A.A. Analysis on exposure carcinogenic risk of environmental factors on health largest industrial cities and malignant tumors. Zdorov'e naseleniya $i$ sreda obitaniya, 2017, no. 2, pp. 57-64 (in Russian).

2. Schüz J., Olsson A. Towards the elimination of occupational cancers in the Russian Federation: cancer research for cancer prevention (Part 1). Meditsina truda i promyshlennaya ekologiya, 2019, no. 2, pp. 104-106. DOI: 10.31089/1026-94282019-2-104-106 (in Russian).

3. May I.V., Kleyn S.V., Vekovshinina S.A., Khankhareev S.S., Madeeva E.V., Zemlyanova M.A., Dolgikh O.V. Hygienic assessment of carcinogenic risk and oncologic morbidity of population living on territories where industrial wastes from an ore mining and processing enterprise were stored. Zdorov'e naseleniya i sreda obitaniya, 2018, vol. 302, no. 5, pp. 40-47 (in Russian).

4. Revich B.A. Population health risks in the chemical pollution hotspots of the arctic macroregion. Problemy prognozirovaniya, 2020, no. 2, pp. 148-157 (in Russian).

5. Turner M.C., Krewski D., Diver W.R., Pope C.A. 3rd, Burnett R.T., Jerrett M., Marshall J.D., Gapstur S.M. Ambient Air Pollution and Cancer Mortality in the Cancer Prevention Study II. Environ Health Perspect, 2017, no. 125 (8), pp. 087013 : DOI: $10.1289 /$ EHP1249

6. National cancer control programs: policies and managerial guidelines, 2nd ed. World Health Organization, 2002. Available at: https://apps.who.int/iris/handle/10665/42494 (06.09.2019).

7. Chromium, Nickel and Welding. IARC Monographs on the Evaluation of Carcinogenic Risks to Humans, IARC Lyon, France, 1990, Vol. 49, 677 p.

(C) Tikhonova G.I., Bryleva M.S., 2021

Galina I. Tikhonova - Doctor of Biological Sciences, Head of the Laboratory for Social and Hygienic Research (e-mail: gtikhonova@yandex.ru; tel.: +7 (495)366-05-66; ORCID: https://orcid.org/0000-0002-1948-4450).

Maria S. Bryleva - Junior Researcher at the Laboratory for Social and Hygienic Research (e-mail: lms_18@mail.ru; tel.: +7 (495) 366-05-66; ORCID: https://orcid.org/0000-0001-7997-979X). 
8. Bukhtiyarov I.V., Izmerov N.F., Tikhonova G.I., Churanova A.N., Gorchakova T.Yu., Bryleva M.S., Krutko A.A. Work conditions as a risk factor mortality increase in able-bodied population. Meditsina truda i promyshlennaya ekologiya, 2017, no. 8, pp. 43-49 (in Russian).

9. Nikanov A.N., Chashchin V.P. Hygienic assessment of exposure and determination of its value in production of nickel, copper and cobalt at mining and smelting complex in Kola high North. Ekologiya cheloveka, 2008, no. 10, pp. 9-14 (in Russian).

10. Rocheva I.I., Leshtaeva N.R. Working conditions and health status of woman employed at the nickel production plants in kola polar region. Ekologiya cheloveka, 2008, no. 10, pp. 47-49 (in Russian).

11. Syurin S.A., Gorbanev S.A. Influence of working conditions and duration of work on health of northern miners. Meditsina truda i promyshlennaya ekologiya, 2018, no. 5, pp. 44-49 (in Russian). DOI: 10.31089/1026-9428-2018-5-44-49

12. Serebryakov P.V. Role of Ni-containing aerosols in development of gastro-intestinal malignant neoplasms. Rossiyskiy zhurnal gastroenterologii, gepatologii, koloproktologii, 2007, vol. 17, no. 3, pp. 78-84 (in Russian).

13. Serebryakov P.V., Fedina I.N., Rushkevich O.P. Features of malignant neoplasms formation in respiratory system of workers engaged into mining and processing of copper-nickel ores. Meditsina truda i promyshlennaya ekologiya, 2018, no. 9, pp. 9-15 (in Russian). DOI: https://doi.org/10.31089/1026-9428-2018-9-9-15

14. Nickel in the Human Environment. IARC Scientific Publications, IARC Lyon, France, 1984, vol. 53, 236 p.

15. Grimsrud T.K., Andersen A. Unrecognized risks of nickel-related respiratory cancer among Canadian electrolysis workers. Scand. J. Work Environ. Health, 2012, vol. 38, no. 6, pp. 503-515. DOI: 10.5271/sjweh.3274

16. Pavela M., Uitti J., Pukkala E. Cancer incidence among copper smelting and nickel refining workers in Finland. Am. J. Ind. Med., 2017, vol. 60, no. 1, pp. 87-95. DOI: 10.1002/ajim.22662

17. Babanov S.A., Budash D.S., Baykova A.G., Ryzhova N.S. Occupational malignant tumors of the lungs and other organs and potentially dangerous industrial carcinogens. Consilium Medicum, 2017, no. 11, pp. 39-46 (in Russian). DOI: 10.26442/2075-1753_19.11.39-46

18. Gurvich V.B., Kuz'min S.V., Lipatov G.Ya., Adrianovskiy V.I., Zebzeeva N.V., Beresneva O.Yu., Bushueva T.V., Ruzakov V.O. The results of the evaluation of carcinogenic hazard with a phased implementation of a set of sanitary and medical preventive measures in the context of copper smelting enterprises. Vestnik Ural'skoy meditsinskoy akademicheskoy nauki, 2015, no. 2, pp. 43-46 (in Russian).

19. Sostoyanie onkologicheskoy pomoshchi na territorii Murmanskoy oblasti. Rossiyskaya assotsiatsiya palliativnoy meditsiny, 2019. Available at: https://palliamed.ru>files/download/file1231.html (06.09.2019) (in Russian).

20. Marshrutizatsiyu onkopatsientov i rabotu tsentrov onkologicheskoy pomoshchi (TsAOP) obsudili mediki Krasnoyarskogo kraya. Ministerstvo zdravookhraneniya Krasnoyarskogo kraya, 2020. Available at: https://kraszdrav.ru/news/8622 (13.02.2020) (in Russian).

21. Artyunina G.P., Chashchin V.P., Ignat'kova S.A., Ostapyak Z.N., Nikanov A.N., Talykova L.V. [et al.]. Problemy professional'noj patologii v nikel'kobal'tovoj promyshlennosti [Problems of occupational pathology in the nickel-cobalt industry]. Gigiena i sanitariya, 1998, no. 1, pp. 9-13 (in Russian).

22. Ciannameo V., Ricceri F., Soldati S., Scarnato C., Gerosa A., Giacomozzi G., d'Errico A. Cancer mortality and exposure to nickel and chromium compounds in a cohort of Italian electroplaters. Am. J. Ind. Med., 2019, vol. 62, no. 2, pp. 99-110. DOI: 10.1002/ajim.22941

23. Tikhonova G.I., Gorchakova T.Yu., Churanova A.N. Mortality among able-bodied population in industrial cities in accordance with specific enterprise forming a company city. Meditsina truda i promyshlennaya ekologiya, 2013, no. 10, pp. 9-15 (in Russian).

24. Ananina O.A., Pisareva L.F., Odintsova I.N., Khristenko E.L., Popkova A.G., Khristenko I.D. Cancer incidence among population of Norilsk. Formation of high risk groups for cancer. Sibirskiy onkologicheskiy zhurnal, 2013, no. 4, pp. 58-61 (in Russian).

25. Goryaev D.V., Tikhonova I.V. Peculiarities of territorial distribution and dynamics in rates of population noncommunicable diseases in the Krasnoyarsk region associated with the influence of environmental risk factors. Health Risk Analysis, 2016, no. 4, pp. 54-63. DOI: 10.21668/health.risk/2016.4.07.eng

26. Karasev V.V., Dettsel' A.E., Shtarik V.A., Dykhno Yu.A. Zabolevaemost' naseleniya Noril'skogo promyshlennogo raiona rakom legkogo [Morbidity with lung cancer among population living in Norilsk industrial region]. Voprosy onkologii, 1992, vol. 11, no. 38, pp. 1340-1344 (in Russian).

27. Egorova A.G., Orlov A.E., Vozdvizhenskiy M.O., Kozlov S.V. State of the oncological care for population of the Samara region and the directions of its improvement. Vestnik novykh meditsinskikh tekhnologiy, 2016, vol. 23, no. 1, pp. 158-164 (in Russian). DOI: $10.12737 / 18502$

28. Edwards B.K., Ward E., Kohler B.A., Eheman C., Zauber A.G., Anderson R.N., Jemal A., Schymura M.J. et al. Annual report to the nation on the status of cancer, 1975-2006, featuring colorectal cancer trends and impact of interventions (risk factors, screening, and treatment) to reduce future rates. Cancer, 2010, vol. 116, no. 3, pp. 544-573. DOI: 10.1002/cncr.24760

29. Loud J.T., Murphy J. Cancer Screening and Early Detection in the 21st Century. Semin. Oncol. Nurs., 2017, vol. 33, no. 2, pp. 121-128. DOI: 10.1016/j.soncn.2017.02.002

Tikhonova G.I., Bryleva M.S. On assessing risk factors that cause mortality due to malignant neoplasms among men living in industrial monotowns. Health Risk Analysis, 2021, no. 3, pp. 67-77. DOI: 10.21668/health.risk/2021.3.06.eng

Получена: 06.02.2021

Принята: 27.07.2021

Опубликована: 30.09 .2021 